\title{
F. Braudel: tempo histórico e civilização material. Um ensaio bibliográfico
}

\author{
Antonio Penalves Rocha \\ Departamento de História, Faculdade de Filosofa, \\ Letras e Ciências Humanas/Universidade de São Paulo
}

A obra Civilização material, economia e capitalismo, um clássico da historiografia contemporânea, cuja tradução brasileira foi publicada em 1995, apresenta o resultado das leituras feitas por Fernand Braudel (1902-1985) ao longo de toda a sua vida. Trata-se de um livro singular em conseqüência do caminho trilhado pelo autor para reconstruir a história do mundo inteiro entre 1400 e 1800, vista como "um Antigo Regime à escala do mundo". Os comentários que se seguem pretendem tecer algumas considerações sobre esse caminho e o papel desempenhado dentro dele pelo estudo da civilização material.

Embora tenha sido publicado pela primeira vez há quase vinte anos, o livro não envelheceu. Tanto é assim que continua interessando aos historiadores profissionais pelo caráter que imprime à história econômica e por estar apoiado em escoras teóricas que o mesmo historiador elaborou noutro trabalho. Continua também despertando o interesse dos demais cientistas sociais, tanto pela erudição do autor quanto pela utilização na pesquisa histórica de ferramentas que usualmente estão nas mãos de economistas, sociólogos, antropólogos, etc. Não bastasse isso tudo, o livro tem tido bastante sucesso junto ao público não especializado, quer seja pela forma com a qual trata o assunto, quer seja pelo inegável talento literário de Fernand Braudel; uma expressão disto, foi o seu sucesso como livro de bolso na França.

A história deste livro principiou no início dos anos 50, quando Braudel foi convidado por Lucien Febvre para fazer uma sintese das pesquisas sobre a história econômica da Europa pré-industrial. O resultado dessa empreitada seria 
transformado num livro da coleção Destins du monde, dirigida pelo próprio Lucien Febvre, que, juntamente com o convite, propôs a Braudel uma espécie de parceria: cuidasse este último daquele assunto e Febvre escreveria um outro volume, cujo título provisório era Pensamentos e crenças no Ocidente, do século XIV ao XVIII. No entanto, a parceria não chegou a bom termo: até 1956, ano da sua morte, Lucien Febvre não havia executado a tarefa que atribuíra a si mesmo. Quanto a Fernand Braudel, o trabalho para por um ponto final no livro se estendeu por cerca de vinte e cinco anos. Assim, em 1967, publicou, nessa mesma coleção, um livro intitulado Civilização material e capitalismo, que tinha o seguinte subtítulo: O possivel e o impossivel: os homens frente à sua vida cotidiana. Na sua Introdução acha-se uma promessa: um segundo volume a ser publicado seria dedicado ao estudo da vida econômica (Braudel 1970: 12).

Mas não foi assim que as coisas aconteceram: a partir de 1967, o historiador trabalhou na revisão do livro, acrescentou a ele outros dois tomos e rebatizou o conjunto, que, finalmente, foi lançado em 1979. Desta feita, passou a se chamar Civilização material, economia e capitalismo - séculos XV-XVIII, composto por três volumes: II As estruturas do cotidiano; II) Os jogos da troca; III) O tempo do mundo. A atual edição brasileira segue estes títulos e esta ordem.

A importância assumida por Civilização material, economia e capitalismo na historiografia está fão diretamente ligada aos seus pressupostos teóricos, que se pode dizer, que nele o método constituiu o objeto. Como tais pressupostos não foram elaborados no livro em questão, só podem ser claramente compreendidos dentro da história da sua própria obra, que, por sua vez, participou do movimento historiográfico francês responsável pela formação da hoje toda poderosa Escola dos Annales.

A reviravolta da historiografia francesa começou em 1929, quandoos historiadores Marc Bloch e Lucien Febvre, que trabalhavam na Universidade de Estrasburgo, encabeçaram um movimento que ensejava modernizar a disciplina histórica. Para tanto, juntaram-se a cientistas sociais e fundaram uma revista, os Annales d'histoire économique et sociale, para ampliar os campos da pesquisa histórica, deixando de lado os campos que até então tinham sido privilegiados, a saber, o campo da biografia, da história do pensamento e da história dos acontecimentos políticos. Mas a consecução deste propósito demandava uma aliança da História com as demais ciências sociais - Geografia, Sociologia, Economia, Psicologia, Lingüística, etc. -, que tinham conhecido um desenvolvimento vertiginoso a partir dos fins do século XIX. Por meio desta aliança, o historiador teria à sua disposição instrumentos para penetrar em territórios que até então não haviam sido sistematicamente explorados pela História, os da história social, da história econômica e daquilo que hoje é conhecido como história das mentalidades. Juntamente com o estabelecimento de novos campos de investigação e de conhecimento do historiador, a revista pleiteava: 1) a instauração de uma história-problema, em oposição à história narrativa, isto é, descritiva dos acontecimentos únicos; 2) a ampliação das fontes de informação histórica, pois o documento escrito era supervalorizado, em detrimento da iconografia, dos vestígios arqueológicos, etc.; e 3l a adoção de uma dialética entre presente e passado, em contraposição à idéia dominante de que o passado era algo separado do mundo do historiador. 
Os historiadores dos Annales jogaram a partida, e venceram-na; desde os fins da II Guerra Mundial, seus preceitos constituíram os alicerces de uma escola historiográfica, que assumiu a hegemonia na historiografia francesa e hoje exerce um verdadeiro imperialismo dentro da História, onde quer que seja.

Quando a revista foi criada, Fernand Braudel, nascido no interior da França em 1902, lecionava História na Argélia; onde permaneceu entre 1923 e 1932. Segundo Braudel, esta experiência profissional fez nascer sua paixão pelo Mediterrâneo; com ela surgiu, em 1929, um projeto de pesquisa, inicialmente intitulado Filipe II, a Espanha e o Mediterrâneo. Para levar a cabo tal projeto, Braudel filmou documentos históricos em diversas cidades da orla mediterrânica.

A busca de algumas orientações sobre o trabalho, entrou em contato com Lucien Febvre, autor de uma tese, defendida em 1911, Filipe ll e o Franco Condado, que, ao analisar um episódio da história diplomática, conservava ainda as marcas do establishment historiográfico francês. De qualquer modo, Lucien Febvre sugeriu - e Fernand Braudel acatou a sugestão - que fosse dado um novo perfil ao objeto: suas atenções deveriam se voltar para as relações entre o Mediterrâneo e Filipe II, quer dizer, era necessário que a pesquisa pusesse em primeiro plano a paisagem e a relação entre homens e meio natural na época de Filipe II, se desvencilhando, assim, da tradicional história dos acontecimentos políticos. De qualquer maneira, Febvre recomendava a Braudel a aplicação dos preceitos de uma nova História ainda em gestação, pois na aliança entre História e Ciências Sociais merecia destaque o reconhecimento dos avanços da Geografia, que incorporara as idéias de Vidal de la Blache. Aliás o próprio Lucien Febvre já havia publicado um livro, em 1922 - A Terra e a evolução da humanidade, introdução geográfica à história - em que destacava as relações entre meio ambiente e história das sociedades.

Entre os anos de 1935 e 1937, Fernand Braudel lecionou na recém inaugurada Universidade de São Paulo. Trouxe para cá os filmes, e deu prosseguimento ao seu trabalho. Na volta à França, viajou no mesmo navio em que estava Lucien Febvre, fato este que marcou o início de uma relação: Febvre "adotou" Braudel como seu filho intelectual; este último aceitou de tal modo a condição que, em 1947, dedicou sua Tese de Doutorado a "Lucien Febvre como prova de reconhecimento e afeto filial".

Com a declaração de guerra da França à Alemanha, Fernand Braudel tornou-se oficial do exército francês, foi feito prisioneiro e, como tal, levado a um campo alemão, onde permaneceu entre 1940 e 1945. No campo de prisioneiros, Braudel continuou trabalhando: escrevia de memória em cadernos escolares os resultados da sua pesquisa e enviava os rascunhos a Lucien Febvre na França.

No que diz respeito aos Annales, quatro mudanças importantes ocorreram entre os fins dos anos 30 e o pós-guerra: primeiro, juntamente com a transferência de Marc Bloch e Lucien Febvre para Paris, a revista mudou de endereço nos fins dos anos 30; segundo, Marc Bloch, que havia se engajado na Resistência, foi preso e, em 1944, brutalmente torturado e por fim assassinado pelos nazistas; terceiro, quando terminou a guerra, Lucien Febvre escolheu Fernand Braudel como seu parceiro para dirigir a revista; este não só aceitou o convite como também permaneceu no cargo até 1968; quarto, com a entrada de Braudel, a revista mudou de nome, passando a se chamar Annales. Économies, sociétés, civilisations, 
nome este que conservou até 1994. Cabe observar que a exclusão do vocábulo História do título indicava a sua maior abertura para outras ciências sociais Antropologia, Demografia, Psicologia Social -, ao passo que o emprego do termo Civilizações traduzia esta nova aliança.

Em 1947, Fernand Braudel defendeu sua Tese de Doutorado, $O$ Mediterrâneo e o mundo mediterrânico na época de Filipe II, publicada em 1949.

O Mediterrâneo... apresenta uma nova concepção do tempo histórico, que foi teoricamente elaborada por Braudel a partir de dados obtidos na sua própria investigação; esta concepção foi transformada pelo historiador num preceito teórico, que se transformou na marca registrada de toda a sua obra, por ter sido aplicado nas suas demais pesquisas ulteriores.

No título do livro já estão representadas as diferentes partes que o formam. Na primeira, o Mediterrâneo; mas não se trata, aos olhos de Braudel, de uma "introdução geográfica", ou seja, a descrição de um espaço ou uma paisagem tidos como pano de fundo de um cenário; ele estava de fato interessado em submeter à análise histórica as relações entre homens, espaço e paisagens; na segunda, tem lugar o mundo mediterrânico, ou seja, as sociedades, economias, estados, civilizações e finalmente, na época de Filipe II, a narrativa de fatos políticos e militares do período.

Seguindo essa ordem, o historiador tinha em vista a reconstrução de uma "história total" do Mediterrâneo nos fins do século XVI. Mas Braudel foi mais longe: obteve da investigação elementos para edificar uma teoria sobre a decomposição do tempo histórico. Explicando melhor, a observação do conjunto da vida do Mediterrâneo e o método de exposição do objeto estudado possibilitaram a Fernand Braudel dividir o tempo histórico em três ritmos, no que diz respeito às mudanças que se processam dentro dele. Assim, ao analisar o Mediterrâneo, ou seja, as relações entre homens e meio ambiente, viu-se frente a uma "história quase imóvel", "história lenta no seu fluir e na sua transformação, feita não poucas vezes de constantes reiterações e ciclos incessantemente reiniciados", "situada quase fora do tempo". Depois disso, há uma outra história, marcada pelo "ritmo lento", a do mundo mediterrânico - economias, sociedades, estados e civilizações -, que se situa acima da "história imóvel". Por fim, ao tratar da época de Filipe ll, encontra a "história tradicional", recortada não "na medida. do homem, mas na medida do indivíduo, a história dos acontecimentos", considerada como "a mais apaixonante, a mais rica em humanidade, e também a mais perigosa. Desconfiemos desta história ainda em brasa, tal como as pessoas da época a sentiram e a viveram no ritmo das suas vidas, breves como as nossas. Esta história tem a dimensão tanto das suas cóleras como dos seus sonhos e das suas ilusões" (Braudel 1953: XVII-XVIII).

Resumindo: Fernand Braudel fez a tripartição do tempo histórico em "um tempo geográfico, um tempo social e um tempo individual". Cada um deles segue um ritmo próprio: assim, o primeiro é quase imóvel; o segundo, lento; o terceiro, fugaz como a vida do indivíduo. Este último era tratado metaforicamente como "a agitação da superfície, as ondas que as marés levantam no seu poderoso movimento" (Braudel 1953: XVIII).

Considerando o esforço dos historiadores dos Annales para deixar de lado a descrição do acontecimento único, dando as costas à "história historizante", 
e para ampliar os territórios de exploração da disciplina histórica por meio de uma aliança com as demais ciências sociais, a formulação de Fernand Braudel tornava-se algo parecido com o ovo de Colombo. Isto porque a análise das sociedades, economias e civilizações exigia que a pesquisa histórica operasse dentro de um tempo mais lento, pois os fenômenos que se manifestam dentro desses campos são marcados pelas regularidades, permanências, continuidades e repetições, isto é, ultrapassam o curto intervalo de tempo ocupado pelo acontecimento singular. No entanto, Braudel foi quem elaborou uma teoria sobre os diferentes ritmos do tempo histórico, cuja formulação completa se encontra no artigo "História e Ciências Sociais: a longa duração", publicado em 1958 nos Annales. Nele sugeriu que a História e todas as demais Ciências Sociais deviam sempre estar atentas às diferentes durações - intervalos de tempo - do objeto estudado, e dar prioridade aos fenômenos de longa duração. Tomando assim o termo duração e empregando-o em O Mediterrâneo e o mundo mediterrânico na época de Filipe II, teríamos a longa duração nas relações entre homens e meio ambiente, haja vista que aí se encontra "uma história quase imóvel" e a curta duração nos acontecimentos da época de Filipe II. As sociedades, economias, estados e civilizações, ficariam entre estes dois extremos, pois se movimentavam dentro de "uma história lenta". No mesmo artigo, Braudel associou a tripartição do tempo a novos conceitos; havia o tempo breve do evento, o tempo dos ciclos econômicos, que é o das conjunturas e também um tempo de amplidão secular, o das estruturas, entendidas como "articulação, arquitetura, porém mais ainda, uma realidade que o tempo utiliza mal e veicula mui longamente" (Braudel 1978: 49).

Cabe fazer mais uma observação sobre a questão da decomposição dos tempos da história. A indicação da existência de diferentes ritmos temporais, não significa que Braudel tivesse tido a pretensão de formular uma completa teoria social, isto é, uma hipótese explicativa da dinâmica das sociedades. O que de fato the interessava era fazer uma "história total", isto é, uma história que quer dar conta de todos os aspectos de uma civilização, analisando todas as manifestações da vida e das atividades dos homens; as condições necessárias para se fazer esta história eram o reconhecimento da existência dos diferentes tempos e o emprego da caixa de ferramentas das Ciências Sociais.

Além do mais, a adoção do princípio da pluralidade dos tempos traria ganhos científicos à História. Isto porque, em primeiro lugar, por meio dele, a História podia se desvencilhar do tempo linear e progressivo das Filosofias da História (hegeliana, comtiana ou marxista), isto é, em vez de recorrer a uma noção apriorística de tempo, o tempo histórico passaria a ser dado pelos próprios objetos da pesquisa. Em segundo lugar, podia também defender-se das investidas de Claude Lévi-Strauss, que desqualificavam a História sob o forte argumento de que seu conhecimento das sociedades permanecia apenas no plano empírico, ignorando os elementos inconscientes da vida social, que, no limite, eram atemporais; dentro desta mesma linha de raciocínio, o antropólogo proclamava, em Antropologia Estrutural, também publicado em 1958, a superioridade da Etnologia, pois ela era capaz de observar a estrutura inconsciente que organizava instituições e costumes, empregando instrumentos da lingüistica. É também como reação a essas idéias de Lévi-Strauss que se compreende por que Fernand Braudel relacionou estruturas com longa duração, ou seja, conferiuthes caráter histórico. 
Enfim, não foi à toa que diversos historiadores classificaram o conteúdo desse artigo como a mais importante contribuição teórica de Fernand Braudel à Escola dos Annales, senão o único princípio teórico da escola efetivamente revolucionário.

Em Civilização material, economia e capitalismo - séculos XV-XVIII, publicado trinta anos depois de $O$ Mediterrâneo e o mundo mediterrânico na época de Filipe II, Fernand Braudel recorreu novamente à tripartição, só que desta feita o objeto não é mais uma região colocada em perspectiva histórica, como fizera no estudo sobre o Mediterrâneo, mas sim uma Europa "alargada à dimensão do mundo", envolvendo, por conseguinte, África, Ásia e América, para um estudo de história econômica.

Até então, os trabalhos dentro desse domínio da historiografia haviam se apoiado na concepção do tempo progressivo, apresentando dados sobre o crescimento econômico e populacional, ov estudando a evolução das atividades econômicas agrícolas, comerciais e manufatureiras. Contudo, a visada de Braudel foi de outra ordem, e dela resultou um esquema composto por três partes - novamente o três. Construiu uma "casa econômica" - expressão que usava sob os protestos de Febvre - de três pisos: no térreo, a vida material, regida pelo signo do valor de uso; acima dele, no primeiro andar, a economia, que "começa no limiar do valor de troca", trazendo à luz relações existentes em dois níveis: 1) "partículas elementares" (tendas de mascates, lojas e feiras) e 2) "seus meios superiores, praças comerciais, bolsas ou grandes feiras"; a partir deste último, que está imbricado no primeiro nivel, desenvolve-se o que chama de capitalismo, "sempre multinacional (...) das Companhias até os monopólios dos nossos dias". No segundo andar, mostrou o nascimento e a cronologia de sistemas econômicos mundiais - as economiasmundo -, estando cada um deles sob o domínio de uma cidade - Veneza, Antuérpia, etc. - ao longo do período que vai do século XV ao início do XIX.

Como se sabe, As estruturas do cotidiano é o produto da revisão do Livro I de Civilização material e capitalismo, que Braudel publicara em 1967, revisão esta que não alterou a organização formal do texto, mas acrescentou dados, fontes e bibliografia. Nele o historiador apresenta aspectos da vida cotidiana de um mundo predominantemente rural do século XV ao XVIII, envolvendo de "80\% a 90\% da população do globo". População: fomes, epidemias, peste, doenças; alimentação: trigo, arroz, milho, batata, massas, laticínios, gordura, ovos, peixe, pimenta, açúcar; bebidas e dopantes: água, vinho, cerveja, sidra, chocolate, chá, café, tabaco; casa, vestuário e moda; técnicas: fontes de energia e metalurgia; moeda e cidades, são os assuntos tratados.

Para Braudel, estes aspectos do dia-a-dia formavam uma "zona de opacidade", que se estendia "sob o mercado", dentro dos "limites do possível no mundo da pré-indústria". "A falta de melhor termo", argumenta, "denominei esta zona espessa, rente ao chão, de vida material ou civilização material. É evidente a ambigüidade da expressão - talvez um dia partilhada pelos economistas - que darão etiqueta mais adequada a esta infra-economia, esta outra metade informal da atividade econômica, a da auto suficiência, da troca dos produtos e dos serviços num raio muito curto" (Braudel 1995, 1: 12).

Para efeitos da análise de Braudel, as atividades da vida material são sempre locais, pois se realizam num "raio muito curto", garantindo a auto-suficiência das populações, o que thes dá um caráter virtualmente autárquico. 
No que diz respeito ao ritmo temporal, esses aspectos da vida material arrastam-se pela força da inércia, "esta grande obreira da história", sendo que "só haverá ruptura, inovação, revolução na vasta linha que separa o possivel do impossivel com o século XIX e a convulsão total do mundo". Deste modo, são regulados pela mesmice, por um "passado obstinadamente presente", que consome o "tempo frágil dos homens". Manifestam-se por meio de "milhares e milhares de faits divers"; mas, como "poeira da história" que são, ao se reproduzirem igualmente, solidificam-se como "realidades em cadeia. Cada um deles serve de testemunha a milhares de outros que atravessam a espessura de tempos silenciosos e duram" (Braudel 1995, I: 5131. Aqui, portanto, não há decisão dos homens, atores que não representam, mas são representados pelo hábito e pela rotina, capazes de ajudá-los a viver, sem que tenham consciência disso. Muitos deles existem desde o começo da história da humanidade; mas, embora sejam muito antigos, continuam vivos, constituindo uma "passado multissecular que deságua no presente, como o Rio Amazonas lança no Atlântico a vasta corrente das suas águas escuras" (Braudel 1979: 8).

Assim sendo, para Braudel; a incessante repetição desses aspectos da vida material das populações pré-industriais tornam-se "séries", "longas durações", isto é, ocupam uma temporalidade que thes é dada pela condição de estruturas. No fim deste volume, o leitor fica sabendo que vida material ou civilização material envolve principalmente três campos: o meio ambiente das sociedades, as bases materiais do cotidiano - alimentação, vestuário, moradia - e as técnicas. E isto é tudo o que se sabe a respeito do assunto na obra As estruturas do cotidiano, pois Braudel adotou aquelas expressões como conceito, sem, no entanto, definitas e delimitar o campo de investigação que thes pertencia dentro do conhecimento histórico. Essa ausência se tornou motivo de debate. De um lado, houve a irritada crítica de Carandini, sobre a inexistência de um estatuto teórico do conceito de "civilização material" no livro de Braudel: "ele fala em termos literariamente sugestivos de "poeiras da história", de "cotidiano inconsciente", de "rés-do-chão da vida econômica", de "nível zero da história", mas o que podemos extrair de tais agudas definições?" (Carandini 1979: 94). De outro, a defesa de Jean-Marie Pesez, marcada pelo espírito de escola, que considera, em primeiro lugar, o mesmo livro como "a primeira grande síntese de história material", para, em seguida, tomar a censura de Carandini como referência e fazer uma afirmação no mínimo discutível: "é certo que tal se verifica la ausência de teorizaçãol, embora mais de uma fórmula saída da pena do escritor francês valha por uma definição, de tal modo ela toca no ponto certo, com uma felicidade de expressão que não tem igual" (Pesez 1978: 104).

Mas talvez a questão da ausência de teorização possa ser mehor compreendida sob um outro prisma: o objeto anunciado tanto no título da primeira edição do livro em 1967, quanto na edição de 1979, é o aspecto propriamente material do cotidiano das sociedades de um Antigo Regime mundial, que Braudel denominou de civilização material ou vida material. Seja qual for o nome dado à coisa, o que de fato importa é que se trata da apropriação pelo historiador de um objeto que havia estado até então sob os cuidados da Etnologia. Este pode muito bem ter sido um dos motivos que fez Braudel se sentir à vontade dentro do campo, eximindo-se da responsabilidade de definilo e de fixar o seu estatuto teórico; o outro parece residir no fato de que o assunto do livro As estruturas do cotidiano foi 
usado para um acerto de contas sobre as relações entre História e Ciências Sociais, como se verá adiante, sem que este procedimento causasse prejuízos ao estudo propriamente dito e ao papel que o livro desempenha no conjunto da obra.

Cumpre destacar que a relação entre História e Etnologia, no que diz respeito ao cotidiano, já foi posta em evidência por Jacques Le Goff: "o contributo imediato da etnologia à história é, sem dúvida, o sublinhar da civilização lou cultura) material" (Le Goff 1985: 194). Vendo as coisas sob esta perspectiva tem -se a impressão que, ao entrar no território da Etnologia, Braudel cumpria uma promessa dos Annales do pós-guerra, pois realizava, no final das contas, um trabalho no campo das civilizações. As estruturas do cotidiano passaria então à condição de ponto alto do processo evolutivo da aliança da História com as demais Ciências Sociais, a partir do qual poder-se-ia afirmar, acompanhando mais uma vez Jacques le Goff, que "a nova história, depois de se ter feito sociológica, tende a se tornar etnológica" (|lb.: 188).

Deve ser lembrado, no entanto, que essa formulação de le Goff manifesta a lealdade de um sucessor de Braudel nos Annales, o que quer dizer que só se pode esperar dele muita delicadeza no trato, atitude esta expressa na noção de "contributo imediato" da Etnologia à História, e esquecer um dos "combates" dos Annales. Com efeito, para quem está do lado de fora, esta entrada de Fernand Braudel na seara alheia pode ser traduzida mais adequadamente por meio de metáforas militares, como, por exemplo, "conquista de território inimigo". Isto porque em As estruturas do cotidiano, o historiador acertou contas com a pretensão hegemônica da Antropologia "estrułural" no terreno das Ciências Sociais, ao mostrar que a História estava capacitada para operar com as estruturas, conferindothes a dimensão temporal. Com efeito, ao analisar o cotidiano dos séculos XV ao XVIII, Braudel demonstrou que a estrutura muda, muito embora pela sua própria condição seja uma realidade que o tempo "utiliza mal e veicula mui longamente", isto é, embora esteja submersa na longa duração, ela participa de uma determinada temporalidade. E tem mais: tal mudança só pode ser apreendida pela observação histórica dentro da dialética das durações: no caso concreto de Civilização material, economia e capitalismo, tanto a expansão da vida material pode afetar o capitalismo, como a expansão do capitalismo pode agir sobre a vida material. $O$ que deve ser destacado é que Braudel não se limitou a descrever as estruturas do cotidiano: pretendeu também demonstrar que elas mudam; é o que se vê, por exemplo, quando afirma que só no século XIX haverá "ruptura, inovação, revolução" nas estruturas do cotidiano, ou que se um homem do século $X X$ visitasse a casa de Voltaire, poderia "ter com ele uma longa conversa sem surpresas. No plano das idéias, os homens do século XVIII são nossos contemporâneos (...) Mas se o mestre de Ferney nos retivesse em sua casa durante alguns dias todos os pormenores da vida cotidiana, até o cuidado que tivesse com sua pessoa, nos surpreenderiam muito. Entre ele e nós abrir-se-iam terriveis distâncias: a iluminação à noite, o aquecimento, os transportes, os alimentos, as doenças, os medicamentos..." (Braudel I 1995: 16).

Desse modo, As estruturas do cotidiano de Fernand Braudel viabilizava a existência de uma História estrutural, mesmo que o seu conceito de estrutura não fosse o mesmo que o de Claude Lévi-Strauss. 
Vale a pena por em relevo uma outra dimensão do mesmo assunto: ao se apropriar de um objeto da Etnologia, Braudel não estaria tão-somente pondo em prática o seu empenho pessoal para criar um "mercado comum" das Ciências Sociais? Caso a resposta tosse positiva, não haveria como explicar a cordial e amigável rivalidade entre Braudel e Lévi-Strauss, que ganhou vida desde que ambos trabalharam na USP e, ainda mais importante, para o historiador "o mercado comum" das ciências do homem só se concretizaria se o evento fosse definitivamente banido dos seus domínios, e se elas o substituíssem pela investigação dos fenômenos de longa duração, ou seja, só se concretizaria sob a hegemonia da história.

Em Os jogos da troca encontra-se o primeiro andar, situado logo acima da "vida material", com a presença de "milhares de pontos modestos: feiras, bancas, lojas...", até "seus meios superiores, praças comerciais, bolsas ou grandes feiras", sendo que o mais "elementar capitalismo", acha-se aí instalado. Apenas uma minoria da humanidade é mobilizada por essas atividades, dado que a grande massa está encapsulada na vida material.

A análise e a exposição que Braudel faz deste conjunto têm em vista "apreender regularidades e mecanismos"., com vistas a apresentar "uma espécie de história econômica geral ou para quem preferir outras linguagens, uma tipologia, ou um modelo" (Braudel 1995, II: 5). Ao lidar com isso tudo, o historiador centraliza este seu estudo "na junção do social, do político e do econômico", ficando o livro "a meio caminho entre a história, inspiradora primordial, e outras ciências do homem".

Em suma, Fernand Braudel fornece dados sobre a "economia de mercado", tomando de empréstimo um conceito que era caro a Karl Polanyi e, ao mesmo tempo, se recusando a usá-lo no sentido específico que este lhe dera em $A$ grande transformação. Nela encontra dois níveis: o das trocas locais, onde verifica que a concorrência flui sem entraves pela ausência de intermediários - produtores e consumidores mantêm contato direto -, e um outro nível superior, onde a circulação das mercadorias - produtos nacionais e internacionais - envolve intermediários, mercadores itinerantes que atuam como agentes econômicos; dentro deste conjunto prosperava o capitalismo, entendido como "esfera de circulação".

Embora estivesse ancorada na vida material, Braudel considerou que a "economia de mercado" era dotada de autonomia relativa, o que lhe assegurava algum movimento próprio. Por isso mesmo, ao contrário da vida material, que se encontra sob o signo da inércia, a "economia de mercado" estava sujeita a um outro ritmo temporal, marcado por mudanças lentas. Tanto é assim, que para Braudel "o capitalismo é essencialmente conjuntural, ou seja, ele floresce de acordo com a ordem das trocas" (Braudel 1979: 61).

Em O tempo do mundo, Fernand Braudel se dedica à construção de uma história "no seu desenrolar cronológico". Neste último andar da casa, reside uma "espécie de superestrutura da história global", "uma espécie de consumação, como que criada e suscitada pelas forças que exercem abaixo dela, embora seu peso repercuta, por sua vez, na base" (Braudel 1995, III: 7). É neste lugar que o historiador procurou apreender "a história econômica do mundo entre os séculos $X V$ e XVII", cujo principal protagonista é o desenvolvimento e modos de ação do capitalismo. Como parte da atuação deste protagonista, destacou o papel exercido por determinadas cidades na constituição de sistemas econômicos internacionais 
- economias-mundo, como os denomina -, baseando-se para isto na análise de um único autor, Immanuel Wallerstein.

Note-se que o capitalismo para Braudel não é um "modo de produção", como o definiram os marxistas, ou ainda, segundo as suas palavras, "um conjunto social", envolvendo "nossas sociedades inteiras", pois existe uma "margem inferior" da economia constituída por "unidades independentes", que ainda hoje, "como no século XVIII, representa de "30 a $40 \%$ das atividades dos países industrializados" (Braudel, III 1995: 585).

Assim, recusa não só a cronologia do capitalismo tal como fora feita por Marx, como também o reconhecintento da sua existência como um sistema de produção baseado na exploração do trabalho assalariado. Para Braudel, a gênese do capitalismo ocorreu bem antes do período em que Marx a localizou, mesmo porque não é na produção que ele reside: "é na circulação, por excelência, que o capitalismo está à vontade"; para afirmar isso, buscou o apoio de uma idéia de Lenin que aparece no Imperialismo, último estágio do capitalismo: "o capitalismo é a produção comercial no seu mais alto nível de desenvolvimento" "(Braudel 1979: 112).

Com efeito, o capitalismo para Braudel é uma estrutura superior, constituída por grupos sociais privilegiados, que se ocupam com cálculos e atuam em áreas da circulação desconhecidas pelo homem comum. Ele difere dos andares inferiores da casa, porque sua regra não é a da concorrência, mas sim do monopólio, e o seu espaço é o do mundo inteiro. O setor capitalista, pelo seu próprio caráter, age com liberdade para selecionar os domínios em que irá intervir, estimulando uns ou abandonando outros à sua própria sorte.

Em resumo, a partir de todos esses dados tem-se o seguinte esquema da "casa" de Braudel: a vida material, na condição de estrutura, regida pela inércia, arrasta consigo o nivel 1 da economia de mercado, constituído por feiras, lojas e tendas; o nível 2, no entanto, "o mais elementar capitalismo". é dotado de mobilidade relativa; ocorre que o seu desenvolvimento e seus modos de atuação implantam sistemas econômicos internacionais - as economias-mundo, cada uma sob a hegemonia de uma cidade; é este último plano que fornece ao historiador uma seqüência cronológica. Por esse caminho, Fernand Braudel submetia, mais uma vez, a história a uma divisão tripartite, tendo agora por objeto a economia pré-industrial: longa duração na vida material, mudanças lentas na economia de mercado e no capitalismo, que, segundo uma imagem sua, não se separam como água e azeite e, finalmente, a curta duração nos eventos das economias-mundo. Distribuídos pelos três livros que formam a obra, a longa duração estaria em As estruturas do cotidiano; o tempo lento, principalmente na segunda parte de $O$ jogo das trocas e, por fim, a curta em O tempo do mundo. Assim, ao efetuar um estudo de história econômica, Fernand Braudel demonstrou, primeiro, que a grade dos diferentes tempos da história podia ser encontrada em outros objetos históricos, e não somente nas relações entre homens e meio ambiente, e, segundo, que a operação historiográfica não deveria se limitar à análise de apenas uma das durações, embora reconhecesse o primado da longa duração; deveria, isto sim;" analisar cada uma em si, para depois verificar no conjunto a dialética das durações.

Enfim, ao priorizar certos aspectos de uma obra, esses comentários não pretenderam tomátlos como única medida para a avaliação dos resultados 
de um trabalho em História. Estes aspectos só adquirem valor como um dos seus elementos, e neste caso merecem destaque por serem indissociáveis de uma obra que expõe o fôlego e a erudição de Fernand Braudel.

\section{BIBILIOGRAFIA CITADA}

BRAUDEL, Fernand. Aftertbougtbs on material life. Baltimore: The Johns Hopkins University Press, 1979.

BRAUDEL, Fernand. Civilização material e capitalismo, séculos XVXVIII. Tradução por Maria Antonieta Magalhães Godinho. Lisboa: Cosmos, 1970.

BRAUDEL, Fernand. Civilização material, economia e capitalismo, séculos XVXVIII: I. As estruturas do cotidiano. II. Os jogos da troca. III. O tempo do mundo. São Paulo: Martins Fontes, 1995. 3v.

BRAUDEL, Fernand. El Mediterraneo y el mundo mediterraneo en la época de Felipe II. Mexico: Fondo de Cultura Económica, 1953.2v.

BRAUDEL, Fernand. História e Ciências Sociais: a longa duração. In: BRAUDEL, Fernand. Escritos sobre a História. São Paulo: Perspectiva, 1978.

CARANDINI, Andrea. Arcbeologia e cultura materiale. Bari: De Donato, 1979.

LE GOFF, Jacques. O maravilboso e o quotidiano no Ocidente medieval. Tradução por José Antonio Pinto Ribeiro. Lisboa: Edições 70, 1985.

MORINEAU, Michel. Un grand dessein: "Civilisation matérielle, économie et capitalisme (XVeXVIII siècles)", de Fernand Braudel. Revue d'bistoire moderne et contemporaine, Paris, n. 28 , out./dez. 1981 .

PESEZ, Jean-Marie. Histoire de la culture matérielle. In: LE GOFF, Jacques (Dir.) La Nouvelle Histoire. Paris: CEPL, 1978. 
The shaping of ecomuseums: elements for analysis and understanding

Heloisa Barbury

This article seeks to trace an overall history of ecomuseums - especially in France - and to detect its roots in folkloristic as well as regional ethnography movements, from the end of the 19th-century until now. Aspects usually underrated are emphasized, as the role of collections and cultural heritage and the museographic patterns.

Uniterms: Ecomuseum. Histoy of the ecomuseum. Museology. Museography. Folklore Museum.

Anais do Museu Paulista, n.sér. v.3, p.209-236, 1995.

F. Braudel: tempo histórico e civilização material. Um ensaio bibliográfico

Antonio Penalves Rocha

A publicação recente da tradução brasileira da obra de Fernand Braudel, Civilisation matérielle et capitalisme, oferece uma boa oportunidade para o reexame de alguns aspectos deste livro. 0 presente ensaio pretende destacar a importância dada por Braudel às questões teóricas - principalmente sua concepção de tempo histórico e seu esforço para criar a unidade das ciências do homem - e o papel que desempenham na delimitação do objeto do livro.

Unitermos: Fernand Braudel. Tempo histórico. Civilização material

Anais do Museu Paulista, n.sér.v.3, p.239-249, 1995.

F.Braudel: historical time and material civilization. A bibliographical essay.

Penalves Rocha

The recent appearance of a Brasilian translation of Fernand Braudel's Civilisation matérielle et capitalisme is a good opportunity to reexamine some aspects of this seminal book and to seek to bound its central object. Special attention is called to the importance assigned by Braudel to some theoretical issues, under the aegis of "material civilization", mainly his concept of historical time and his effort to unify the social sciences.

Uniterms: Fernand Braudel. Historical time. Material civilization.

Anais do Museu Paulista, n.sér. v.3, p.239-249, 1995

Indumentária e moda: uma seleção bibliográfica em Português

Adilson José de Almeida

Foram descritivamente listados livros e capítulos de livros, traduzidos ou originalmente escritos em português, entre 1979 e 1996 e referentes a vários aspectos da indumentária e da moda. O objetivo é fornecer um quadro de referência de acesso imediato tanto para o especialista, como para o leigo. A lista propriamente dita está precedida por uma caracterização geral da bibliografia e por um tratamento mais demorado daqueles autores que se considerou representarem algumas importantes vertentes neste domínio.

Unitermos: Indumentária. Moda. Bibliografia seletiva e descritiva.

Anais do Muscu Paulista, n.sér. v.3, p.251-296, 1995.

Clothes and fashion: a select bibliography in Portuguese

Adilson José de Almeida

Books and book chapters, originally witten in Portuguese or translated into it, fom 1979 to 1996 , and related to several aspects of clothes, clothing and fashion are listed in order to provide an easily available frame of references for specialists as well as for laymen. The listing is preceded by a brief characterization of the bibliography and by a more detailed treatment of those authors considered to represent some impotant streams in this field.

Uniterms: Clothes. Fashion. Select descriptive bibliography Anais do Museu Paulista, n.sér. v.3, p.251-296, 1995 